\title{
The Empirical Study of Logistics Service Quality Evaluation within Electronic Retail
}

\author{
Xiang-Yi ZHOU ${ }^{1, a,{ }^{*}}$, Dong-Mei WANG ${ }^{2, b}$, Yi LIU ${ }^{2, c}$ \\ ${ }^{1}$ School of Information Management and Information System, \\ Beijing Linye University, Beijing 100044, China. \\ ${ }^{2}$ School of Economics and Management, \\ Beijing Jiaotong University, Beijing 100044, China. \\ azhouxiangyi1998@163.com, ${ }^{\text {b dmwang@bjtu.edu.cn, }{ }^{\text {c}} 16120581 @ b j t u . e d u . c n}$ \\ *Xiang-Yi ZHOU
}

Keywords: Electronic retail, Logistics service quality, Customer satisfaction, Customer loyalty, Customer trust.

\begin{abstract}
With the rapid development of Internet, online shopping is more and more popular. At the same time, the return of online shopping is becoming more and more frequent .In order to improve the online shopping experience, logistics service has become the important factors influencing the vigorous development of online shopping. Integrating the traditional theories of Service Quality and Logistics Service Quality Measures, the study will conduct some empirical manner to investigate the e-logistics problem within online shopping business. Considering the particularity of e-commerce logistics service under the return situation, this paper, on the basis of reading lots of literature at home and abroad, set up scientific electronic retail logistics service quality perception (ERLSQ - CP) evaluation model. In this paper, we study logistics service quality and customer satisfaction, loyalty and trust relationship of mutual influence under the return situation, to provide online shopping service quality improvement basis and suggestion and to enhance competitiveness.
\end{abstract}

\section{Introduction}

Academic editor Editorial defined logistics services as "activities that satisfy customer needs, ensure customer satisfaction, and win corporate praise" [1]. Mentzes et al. believed that logistics services should include two layers of meaning; customer marketing services and physical distribution services (PDS). They studied the literature on logistics services over the past 40 years, integrated a large amount of information on logistics distribution and customer service, and finally selected the following three items from 26 factors as indicators for measuring PDS: availability, timeliness and quality of goods. However, these three indicators are actually just the physical distribution indicators in the overall logistics service quality. This is one-sided in terms of the overall logistics service quality [2]. The latest and more complete definition of the overall quality of logistics services was the result of the study conducted by the University of Tennessee. Through in-depth investigation of large third-party logistics companies and customers, they finally concluded nine indicators for measuring the quality of logistics services from the perspective of customers. In the study of logistics service quality, this article focuses on the relationship between logistics service quality and customer perception in the case of return and exchange, and it is more helpful to understand the importance of logistics service quality when the return and exchange situation exists.

\section{Theoretical Assumptions and Model Establishment}

The returned goods belong to reverse logistics. This article refers specifically to the goods buying online which were returned due to various reasons, such as consumers' dissatisfaction with goods or damaged products. According to Parasuramanl et al.'s E-S-QUAL and E-RecS-QUAL scales for online transactions in the form of Internet, such as e-commerce, the quality of online shopping 
logistics service (ERLSQ) in the case of return and exchange is divided into three dimensions, which are responsive, compensatory and communicative.

\section{The Relationship between Logistics Service Quality and Customer Satisfaction and Trust}

The satisfaction-retention-profit model believes that the increase in product/service quality will lead to an increase in customer satisfaction, while an increase in customer satisfaction will make customers more loyal and ultimately make the company more profitable. In the existing literature, many scholars' studies have shown that there is a clear relationship between service quality and customer perception. Zeithaml, Parasuraman and Malhotra gave a clear definition of the concept of service quality under the network environment, analyzed and discussed the components of service quality in the context of the network, and put forward a model of website service quality. The conclusions of the research indicated that for the service quality in the context of the network, it should be related to certain perceived values. Research on service quality and perceived value can help further improve service quality [3,4]. Ping HU (2014) believed that customer satisfaction in logistics services is one of the core competencies of B2C companies.

\section{The Relationship between Customer Trust and Satisfaction}

Kim, Hye-Ran. Developing (2005) found that high trust can bring consumer satisfaction and there is a positive correlation between the two factors. Based on their research, Lee Delene and Bunda (2003) further studied the relationship between customer trust and customer satisfaction when there is a difference in service quality. The study found that high quality of service leads to higher customer perception [5].

\section{The Relationship between Customer Trust, Satisfaction and Loyalty}

Smith (2001) believed that satisfaction experience determines customer trust, customer trust affects customer emotions, and customer sentiment is a guarantee for enterprise development and profitability; Woodruff (2009) believed that customer sentiment is the customer's cognitive response to the company's products, and perceived value reflects the essential relationship between the company, customers, and service quality.

By summarizing the above scholars' views, the author believes that there is a chain of causality between customer satisfaction, loyalty, and trust. The important prerequisites for customers to generate emotions for goods are customer satisfaction and trust, and satisfaction is the premise of trust and loyalty, which has a direct impact on both. The former reason is satisfaction and trust, and the result is loyalty. Satisfaction also has an effect on trust. Based on this, the author proposes the theoretical model of the study, including the following 9 hypotheses. Figure 1 shows the path assumptions among the variables in the ERLSQ-CP model.

According to the above model, the following assumptions are made:

H1: Responsiveness has a significant positive effect on satisfaction

H2: Compensatory has a significant positive effect on satisfaction

H3: Communication has a significant positive effect on satisfaction

H4: Responsiveness has a significant positive effect on trust

H5: Compensation has a significant positive effect on trust

H6: Communication has a significant positive effect on trust

H7: Satisfaction has a significant positive effect on trust

H8: Satisfaction has a significant positive effect on loyalty

H9: Confidence has a significant positive effect on loyalty 


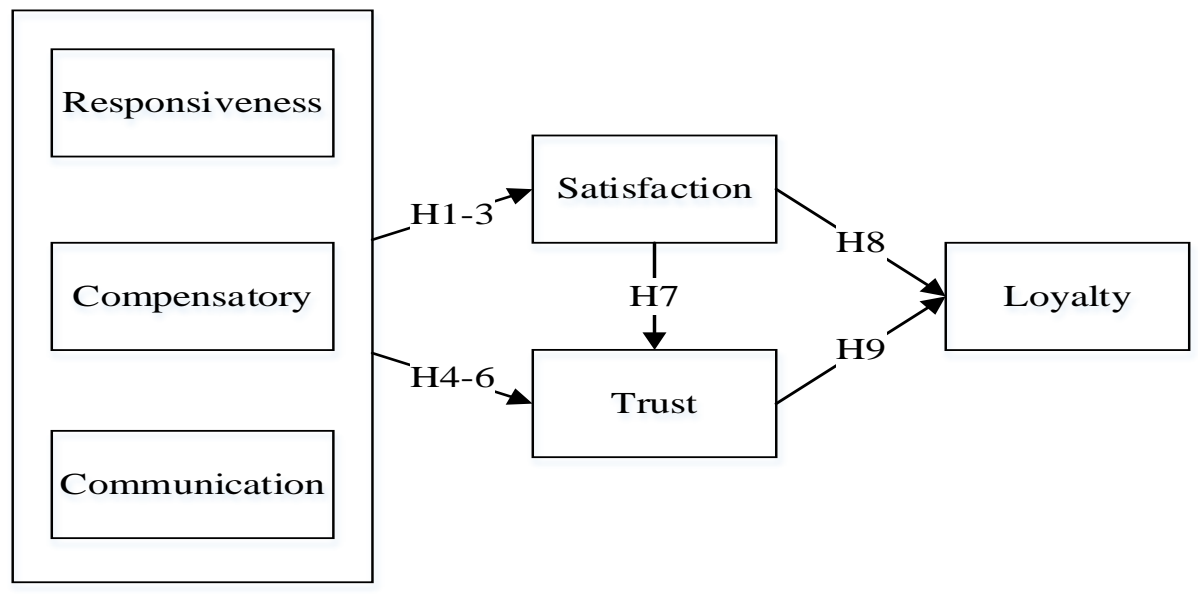

Fig1. Path assumptions between variables in the ERLSQ-CP model

\section{Research Design}

\section{Questionnaire Design and Data Collection}

To ensure the reliability and validity of the test scale, this study adopts mature scales that have been used at home and abroad as much as possible. In this study, a test questionnaire was generated through the construction of the model. Before the large-scale questionnaire was issued, the questionnaire was pre-tested and the validity of the questionnaire was analyzed. Considering that online questionnaires are distributed mainly because Internet users are a major part of online shopping consumers, the results obtained by Internet users conducting this survey should be more persuasive and effective. In this study, the Likert 5 scale was used, and each measurement item consisted of 3 to 5 questions. The scores for the degree of recognition and attitude are never satisfied (disagree) with satisfaction (agreement), and a corresponding 1-5 assignment is performed. 300 questionnaires were published online and 259 were actually recovered, of which 227 were valid and the effective questionnaire rate was $76 \%$. Next, the validity of the questionnaire will be analyzed.

\section{Reliability and Validity Analysis}

\section{Reliability Test}

The reliability of the questionnaire collected from the survey was analyzed to see if it had internal consistency. The results obtained are shown in Table 1.

Table 1. Total correlation coefficient

\begin{tabular}{|c|c|c|c|}
\hline Item code & CICT & $\begin{array}{l}\text { The alpha coefficient after } \\
\text { deleting the question }\end{array}$ & Alpha coefficient \\
\hline Responsiveness 1 & .572 & .801 & \multirow{5}{*}{0.823} \\
\hline Responsiveness 2 & .647 & .780 & \\
\hline Responsiveness 3 & .683 & .769 & \\
\hline Responsiveness 4 & .549 & .814 & \\
\hline Responsiveness 5 & .655 & .777 & \\
\hline Compensatory 1 & .714 & .672 & \multirow{3}{*}{0.807} \\
\hline Compensatory 2 & .679 & .712 & \\
\hline Compensatory 3 & .578 & .813 & \\
\hline Communication 1 & .448 & .739 & \multirow{3}{*}{0.719} \\
\hline Communication 2 & .557 & .608 & \\
\hline Communication 3 & .618 & .529 & \\
\hline
\end{tabular}


Based on the structure of the reliability analysis of the scale in the above table, it was found that the CICT values of the compensation 3 and communicative 1 items are relatively low. The results of the two items in the pre-test are also not ideal, but considering that the number of items and the sample size of the questionnaire are few, and if these two items are deleted, the alpha coefficient of the scale will be increased, so they are retained. However, in the official questionnaire, the reliability of these two items is still not high, so the two items are removed according to the relevant theories.

\section{Validation Test}

In order to test the rationality of the questionnaire design, the degree of structural impact of each variable on the customer's evaluation was tested, and the rationality of each indicator's classification in the questionnaire was tested.

1) Content validity. The conclusion of each item in this article is a reference to a large number of documents, which basically include the links that should be experienced when returning. The form of the questionnaire and the expression of the language are also clearer, and it can be considered that the scale has a good content validity.

2) Structure validity. In the following, factor analysis and correlation analysis are mainly used to test the degree of agreement between the envisioned scale structure and the measured structure. From KMO and Bartlett's Test, the KMO value is 0.833 , which is suitable for factor analysis. The significant probability in the table is 0.000 , less than $1 \%$, indicating that it is relevant and suitable for factor analysis. After orthogonal rotation, three factors were extracted, which corresponded to the three research variables of responsiveness, compensation, and communication in the study. The variation of cumulative explanatory variance was $66.868 \%$.

From table 2, it can be seen that the load of each item in its related factors is greater than 0.5 , and the load factor on other factors is relatively low, indicating that there are good convergence and discriminant validity between the dimensions of this study.

Table 2. Component matrix after the axis

\begin{tabular}{|l|l|l|l|}
\hline & \multicolumn{4}{|l|}{ Component } \\
\cline { 2 - 4 } & 1 & 2 & 3 \\
\hline Responsiveness 1 & .704 & -.126 & .386 \\
\hline Responsiveness 2 & .797 & .111 & .104 \\
\hline Responsiveness 3 & .720 & .227 & .305 \\
\hline Responsiveness 4 & .616 & .223 & .205 \\
\hline Responsiveness 5 & .759 & .333 & .063 \\
\hline Compensatory 1 & .322 & .836 & .048 \\
\hline Compensatory 2 & .240 & .836 & .047 \\
\hline Compensatory 3 & -.45 & .761 & .291 \\
\hline Communication 1 & .393 & .043 & .629 \\
\hline Communication 2 & .067 & .139 & .854 \\
\hline Communication 3 & .405 & .284 & .670 \\
\hline
\end{tabular}

\section{Correlation Analysis and Hypothesis Testing}

\section{Correlation Analysis}

Table 3 shows the correlation coefficients between variables. It can be seen that during the hypothetical groups of relationships, related technologies all have statistical significance. The 
original hypothesis is basically verified.

\section{Hypothesis Testing}

A hypothesis testing was performed on the collected data using AMOS 7.0 statistical software. Table 4 shows the parameters of the model's fitting degree.

Table 3. Correlation coefficient tables of variables

\begin{tabular}{|l|l|l|l|l|l|l|}
\hline & Responsiveness & Compensatory & Communication & Satisfaction & Loyalty & Trust \\
\hline Responsiveness & 1 & & & & & \\
\hline Compensatory & $.461^{* *}$ & 1 & & & & \\
\hline Communication & $.532^{* *}$ & $.367^{* *}$ & 1 & & & \\
\hline Satisfaction & $.598^{* *}$ & $.539^{* *}$ & $.558^{* *}$ & 1 & & \\
\hline Loyalty & $.488^{* *}$ & $.232^{* *}$ & $.489^{* *}$ & $.564^{* *}$ & 1 & \\
\hline Trust & $.553^{* *}$ & $.484^{* *}$ & $.444^{* *}$ & $.672^{* *}$ & $.608^{* *}$ & 1 \\
\hline \multicolumn{7}{|l|}{ *orrelation is significant at the 0.01 level (1-tailed) } \\
\end{tabular}

Table 4. Fit degree correlation coefficient table of ERLSQ-CP model

\begin{tabular}{|l|l|l|l|}
\hline $\begin{array}{l}\text { Each fitting } \\
\text { evaluation index }\end{array}$ & Expected value & Actual value & Acceptable \\
\hline $\begin{array}{l}\text { Chi-square } \\
\text { value }\left(\mathrm{x}^{2}\right) \mathrm{dfx}^{2} / \mathrm{df}\end{array}$ & $\mathrm{x} 2 / \mathrm{df}$ should be less than 3 & 1.60 & Accepted \\
\hline GFI & Greater than or equal to 0.9, indicating that the & 0.806 & Accepted \\
\hline IFI & $\begin{array}{l}\text { model fit is good, between 0.8 and 0.9, } \\
\text { indicating that the model's degree of fit is } \\
\text { acceptable }\end{array}$ & 0.919 & Accepted \\
\hline AGFI & $\begin{array}{l}\text { A value less than } 0.05 \\
\text { between } 0.05 \text { indicates a good fit, } 0.10 \text { indicating that the fit is } \\
\text { acceptable }\end{array}$ & 0.069 & Accepted \\
\hline CFI & & Accepted \\
\hline RMSEA & & Accepted \\
\hline
\end{tabular}

Modifying the model according to the MI value makes the RMSEA value greatly improved compared with the original model. The fitting indexes of GFI, AGFI, IFI, and CFI have been significantly improved compared to the original model, and the model's fitting degree has been optimized. The ERLSQ-CP model is validated as acceptable. Next, through the model's path data analysis, the correlation and path values are obtained. The results are shown in Table 5.

Table 5. Hypothesis Test Results of ERLSQ-CP Model

\begin{tabular}{|c|c|c|c|c|c|}
\hline Assumptions and paths & Estimate & S.E. & C.R. & $\mathrm{P}$ & Label \\
\hline Satisfaction<---Responsiveness & .307 & .113 & 2.717 & .007 & Accepted \\
\hline Satisfaction<----Compensatory & .189 & .071 & 2.662 & .008 & Accepted \\
\hline Satisfaction<---Communication & .184 & .077 & 2.379 & .017 & Accepted \\
\hline Trust $<---$ Satisfaction & .765 & .191 & 4.004 & $* * *$ & Accepted \\
\hline Trust<---Responsiveness & .107 & .121 & .886 & .375 & Not accepted \\
\hline Trust $<---$ Compensatory & -.016 & .078 & -.210 & .834 & Not accepted \\
\hline Trust $<---$ Communication & -.002 & .071 & -.027 & .979 & Not accepted \\
\hline Loyalty<---Satisfaction & .410 & .212 & 1.928 & .054 & Basically Accepted \\
\hline Loyalty<---Trust & .608 & .207 & 2.939 & .003 & Accepted \\
\hline
\end{tabular}

The first column on the right is the non-standardized regression coefficient; the second column is the standard error of the estimated parameter, the standard error of the estimated parameter does not 
appear with the extreme value; the third column C.R. is the test statistic (critical ratio). The critical ratio is the t-test t-value; in the fourth column, the value of $\mathrm{P}$ is significant. If $\mathrm{P}<0.001$, it will be represented by the symbol “***”. If the $\mathrm{P}$ value is greater than 0.001 , the value of $\mathrm{P}$ will appear directly. The critical value are $0.886,-0.21$ and -0.027 .They are all less than the t value which should reach the number of 1.96 . And the significance probability $\mathrm{P}$ is 0.375 which is greater than 0.5 . Therefore, the relationship between logistics service quality responsiveness, compensation and communication, and customer trust has not been effectively supported by data. This shows that in the online shopping environment, the non-linear relationship between logistics service quality and customer trust still exists, and there is a regulatory or intermediary variable between satisfaction of the logistics service quality and customer trust. Thus we can understand the influence of satisfaction on customer loyalty and the adjustment between logistics service quality and customer perception.

Through the path data analysis of the model, the correlation and path values are obtained. The result of the operation is shown in Figure 2.

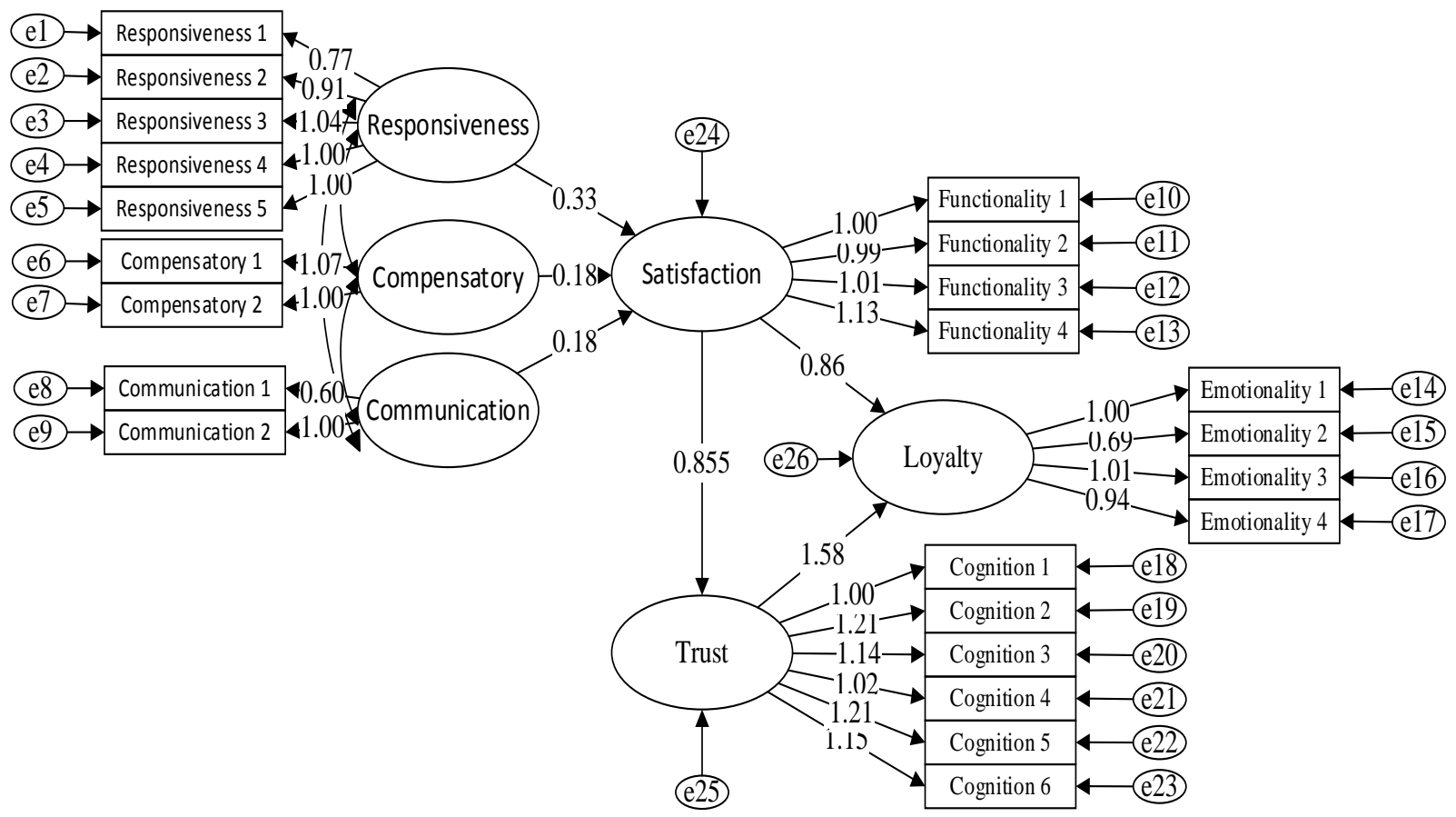

Fig 2. Structural Equation Model Operation Results

\section{Conclusion}

Based on the hypothesis test, this article focuses on the relationship between online shopping logistics service quality and customer perception in the case of return and exchange. It can be seen that ensuring the punctuality of the delivery of the goods, improving the reliability of the delivery, and improving the responsiveness to the needs of the users in the case of returning goods have an important influence on improving the customer satisfaction of online shopping. In addition to improving the customer satisfaction experience, online retailers can also retain loyal customers by increasing the trust experience. Therefore, on the one hand, online retailers should increase customer trust and retain loyal customers in terms of quality of products and services, close relationships with customers, etc.; on the other hand, Chinese logistics service providers need to accelerate the transformation from traditional logistics to information logistics to adapt to the development characteristics of online shopping business. 


\section{References}

[1]. Editorial.Research and applications in e-commerce and third-party logistics management[J].Int.J.Production Economics,2008,113:123-126.

[2]. MENTZER JT,FLINTD J,KENTJL.Developing a Logistics Service Quality Scale[J].Journal of Business Logistics,1999,20(1):29-32.

[3]. Zeithaml. VA-Customer Perceptions of Price, quality, and value: A Means-End Model and Synthesis of evidence[J]. Journal of Marketing. 1988. 52(7): 2-22.

[4]. Parasuraman. The Impact of Technology on The Quality-Value-Loyalty Chain: A Research Agend.[J].Journal of The Academy of Marketing Science, 2000,28:158-166.

[5]. Hee Andy, Lee,Carolyn U. Lambert. The Influence of Technology-Enabled Customer Relationship Management on Customers' Attitude Toward Service Quality and Loyalty.[J].Journal of Food service Business Research, 2008,363:367-37. 